\title{
Theorotical Exergy Analysis of Actual Vapour Compression System with HFO-1234yf and HFO- 1234ze as an Alternative Replacement of HFC-134a
}

\author{
Shobhit Mishra ${ }^{1}$, M. Emran Khan ${ }^{2}$ \\ ${ }^{1}$ Scholar, Masters Degree, Thermal Engineering in Department of Mechanical Engineering, Jamia Millia Islamia, Delhi ( India), \\ ${ }^{2}$ Professor Mechanical Engineering Department, Jamia Millia Islamia, Delhi, (India)
}

\begin{abstract}
This paper deals with the comparison of hydrofluoroolefins (HFO-1234yf \& HFO-1234ze) and HFC-134a in a vapor compression system equipped with liquid vapour heat exchanger(LVHE). HFO-1234ze (trans-1, 3, 3, 3-tetrafluoroprop-1-ene) and HFO-1234yf (2,3, 3, 3-Tetrafluoropropene) have ultra low Global Warming Potential (GWP) and zero Ozone Depletion Potential (ODP). For exergy analysis a mathematical computational model has been developed in Engineering Equation Solver(EES) for calculating different parameters. Results obtained indicates that hydrofluoroolefins (HFO-1234ze and HFO-1234yf) can be a good drop in replacement of $R-134 a$. During the analysis, condenser temperature is $313 \mathrm{~K}$ and evaporator temperature is taken in the range from $233 K$ to $278 K$.
\end{abstract}

Keywords: COP, Exergetic Efficiency, GWP, HFC-134a, HFO-1234ze, HFO-1234yf.

\section{Introduction}

Refrigerating machine is a device which is used to produce lower temperature as compared to surrounding while undergoing in a cycle. Lower temperature are produced by various refrigerants (refrigerants are the substances which are used to produce lower temperature). The performance of the refrigeration system mainly depends on the types of refrigerants, but there are several environmental factors which put restraints on some type of refrigerants, that are extremely hazardous to environment, causes (ODP) ozone layer depletion (i.e CFCs) and (GWP) global warning potential(i.e HFCs and HCs). The Clean Air Act Amendments were passed by the U.S. Congress in 1990 and the Montreal protocol (UNEP, 1987) states the phasing out of $\mathrm{CFC}^{\mathrm{ce}} \mathrm{s}$ and $\mathrm{HCFC}^{\mathrm{ec}} \mathrm{s}$ refrigerants that deplete the ozone layer[6],[7]. United Nations Framework Convention on Climate Change (UNFCCC,1997), held in Kyoto, proposed „Kyoto Protocole ${ }^{\text {ee }}$ to control emission of greenhouse gases including $\mathrm{HFC}^{\text {ces }}$ [5]. Problem of global warming potential is still associated with some of the newer refrigerants. The GWP of R-134a is 1430, hence needs to be replaced by more eco-friendly refrigerants. The alternative refrigerants with a GWP (GWP = 100 year warming potential of one kilogram of a gas relative to one kilogram of $\mathrm{CO}_{2}$ ) of 150 or less should be adopted by original equipment manufacturers(OEMs) and suppliers according to the new legislation by the European union's F-gas regulation No 842/2006[8]. Phasing out of the use of

HFC-134a in mobile air conditioning system for all new models beginning in 2011 according to F-gas regulation. Extensive research and various experiments is being carried out globally to develop the refrigerant that have low GWP to support the refrigeration and air conditioning industry, for example HFA-1234yf and HFA-1234ze. HFO-1234yf and HFO- 1234ze which have a 100 year GWP of 4 and 6 as compared to that of $\mathrm{CO} 2$ could be used as "near drop-in replacement" for HFC134a[1],[2],[3],[4]. HFO-1234yf has a global warming potential (GWP) rating 335 times less than that of R-134a. Infact from 2013 onwards General motors has started using "hydrofluoroolefin", HFO-1234yf in all of its brand. HFO-1234yf developed to meet the European directive 2006/40/EC that went into effect in 2011 requiring that all new car platforms for sale in Europe use a refrigerant in its AC system with a GWP below 150[8].

Leck[10] have reported the results of an atmospheric modeling study in which he found that replacing HFC-134a in vehicle air conditioning units with HFO-1234yf would have little, or no, impact on tropospheric ozone levels (impact was less than $0.01 \%$ of total ozone formed during the simulations). Chi-Chuan Wang[20] analyzed the system performance of HFO-1234yf refrigerant in comparison to R134a in air-conditioning and heat pump system. From his work he found out that the COP and heat capacity of R-134a system may suffer from direct drop-in via R-1234yf. He also found that the condenser performance for R-1234yf is appreciably lower than that of R-134a.

Navarro-Esbri[17] analysed that the cooling capacity of R1234yf used as a drop-in replacement for R-134a in a vapour compression system and reported, that the cooling capacity of R-1234yf is about 9\% lower than that of R134a in the test range which diminishes with the use of internal heat exchanger. Secondly he also found that the COP using R$1234 y f$ are about 5\% 30\% lower than those obtained with R134a. Thirdly he also stated that the volumetric efficiency of R-1234yf is about 5\% lower in comparison with that obtained with R134a. Jarall[21] experimentally found that the refrigeration capacity and COP for R-1234yf relative to R-134a are decreased by $3.4-13.7 \%$ and $0.35-11.9 \%$, respectively. He also concluded that at similar conditions R1234yf has lower pressure ratio than R134a which reduces the compressor power consumption.

Lee and Jung[12] experimentally shows that the COP of R$1234 y$ is $0.8-2.7 \%$ lower than $\mathrm{R}-134 \mathrm{a}$. He also stated that the capacity of R-1234yf is up to $4.0 \%$ lower than that of R134a. Secondly he also found out from his work that the 


\section{International Journal of Science and Research (IJSR) \\ ISSN (Online): 2319-7064}

Index Copernicus Value (2013): 6.14 | Impact Factor (2015): 6.391

compressor discharge temperature of $\mathrm{R}-1234 \mathrm{yf}$ is $6.4-6.7^{\circ} \mathrm{C}$ lower than R-134a. Thirdly he also find out that the amount of refrigerant charge of R-1234yf is $10-11 \%$ lower than that of R-134a. Leighton [13] theoretically showed that HFO1234yf had 9\% lower COP and 6\% less capacity than HFC134a and also showed HFO-1234ze had 8\% higher COP and 21\% lower capacity than HFC-134a.

Abdelaziz[14] calculated experimentally and compared the performance of HFC-134a to HFO-1234yf and HFO$1234 \mathrm{ze}$, and concluded that HFO-1234yf had 2.7\% higher energy consumption than HFC-134a, indicating that HFO$1234 y f$ is a suitable drop-in replacement of HFC-134a in domestic refrigerators. While HFO-1234ze had 16\% lower energy consumption than HFC-134a, hence to replace HFC134a with HFO-1234ze lower capacity refrigerators were required, thus HFO-1234ze might not be suitable for drop-in replacement.

Zhao[18] experimentally analysed that the optimum refrigerant charge amount of R-1234yf was approximately 95\% as compared to R-134a for the same system. Secondly he also stated that in all working conditions, the cooling capacity of the R-134a system was found to be $12.4 \%$ larger than R-1234yf system almost, and the COP of the R-134a system was found to be only 9\% larger, hence HFO-1234yf is a near drop-in-replacement.

Motta[11] analyzed the vapour compression cycle with HFO-1234yf and HFO-1234ze and HFC -134a. and he concluded the following result, firstly R-1234yf shows 1-2\% lower COP but reveals $2-5 \%$ higher capacity as compared to R-134a. Secondly, R-1234ze shows 7-9\% lower COP but reveals $11-13 \%$ higher capacity as compared to R-134a .

\subsection{Applications}

The choice of refrigerant for a given application is governed mainly by the refrigeration capacity ( very small, small, medium or large), and refrigeration temperature[19],

1. Air conditioning $\left(5^{\circ} \mathrm{C}\right)$

2. Cold storage ( -10 to $2^{\circ} \mathrm{C}$ )

3. Refrigerator $\left(-25^{\circ} \mathrm{C}\right)$

4. Food freezing $\left(-40^{\circ} \mathrm{C}\right)$

Table 1: Characteristic Properties Of "Hydroflouroollefins"

Characteristic
properties
formulae
Molarmass $\left(\mathrm{g} \mathrm{mol}^{-1}\right)$
Critical temperature $(\mathrm{K})$
Critical density $\left(\mathrm{kg} \mathrm{m}^{-3}\right)$
Critical molar
volume $\left(\mathrm{cm}^{3} \mathrm{~mol}^{-1}\right)$
Critical pressure $(\mathrm{MPa})$
Normal boiling
point $(\mathrm{K})$
Vaporpressure $(\mathrm{MPa})$
At $273 \mathrm{~K}$
Acentric factor
100 -yr GWP

[9]

R-1234ze R-1234yf

\section{$\mathrm{CHF}=\mathrm{CHCF} 3$}

114.0416

382.51

486

235

3.682

254.2

0.2154

0.313

6

114.0416
367.85
478
238.6

3.382
243.7
0.3142
0.276
4

\section{Exergy Analysis}

From second law of thermodynamic exergy analysis is useful for improving the efficiency of energy resources use, since it quantifies the locations, types and magnitude of losses. Exergy analysis is a powerful tool in the design, optimization, and performance evaluation of energy system. It is defined as the maximum work obtainable in a process as the system comes in equilibrium with the surrounding. First law is the law of conservation of energy or quantitative law while second law is the law of degradation of energy or qualitative law [15].

From first law of thermodynamics, COP represents running cost of the system higher the COP, lower is the running cost of the system. COP is defined as the ratio of refrigerating effect to the work input required. COP is the measure of effectiveness and performance of the cycle and is given as,

$$
\mathrm{COP}=\frac{\dot{Q \mathrm{e}}}{\dot{\mathrm{W}} \mathrm{comp}},
$$

$\dot{Q}_{\mathrm{e}}=$ Rate of heat transfer in evaporator $(\mathrm{kW})$

$\dot{W}_{\text {comp }}=$ Rate of work input to compressor $(\mathrm{KW})$

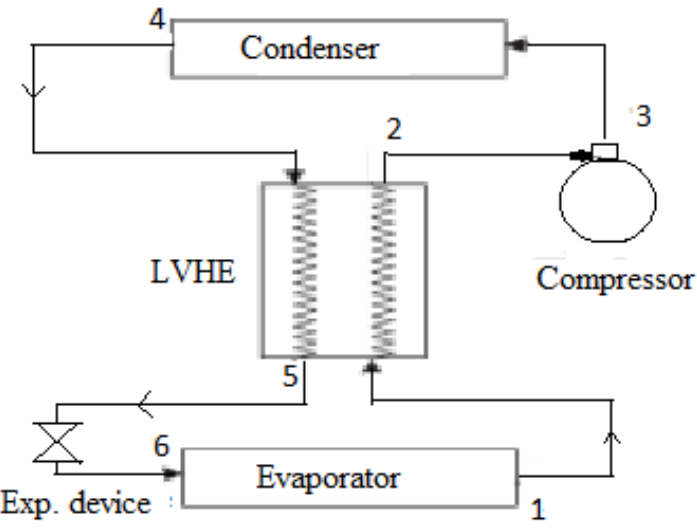

Figure 1: Vapour compression cycle with LVHE.

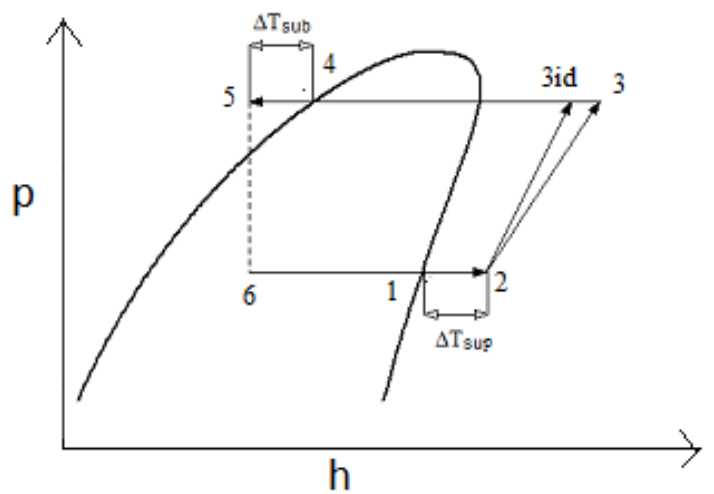

Figure 2: Pressure - Enthalpy diagram of vapour compression cycle with LVHE. 


\section{International Journal of Science and Research (IJSR) \\ ISSN (Online): 2319-7064}

Index Copernicus Value (2013): 6.14 | Impact Factor (2015): 6.391

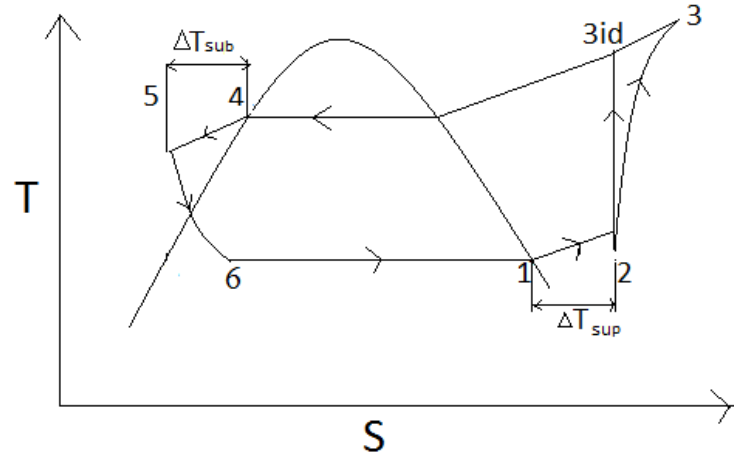

Figure 3: Temp-Entropy diagram of vapour compression cycle with LVHE.

Fig 1- 3,above shows the schematic representation of vapour compression cycle equipped with liquid vapour heat exchanger on T-s and P-h diagram.

Exergy balance for a control region in a steady state process is given below as,

$$
\dot{\mathrm{Z}}_{\mathrm{i}}+\dot{\mathrm{Z}}_{K}^{Q}=\dot{\mathrm{Z}}_{\mathrm{e}}+\dot{\mathrm{W}}+\mathrm{ED}
$$

where,

$\dot{\mathrm{Z}}_{\mathrm{i}}=\sum_{I N} \dot{m} \mathrm{z}$, exergy flow rate of the component entering the control region $(\mathrm{KW})$

$\dot{\mathrm{Z}}_{\mathrm{e}}=\sum_{\text {out }} \dot{m} z$, exergy flow rate of the component leaving the control region(KW)

Above equation are valid by neglecting kinetic exergy and potential exergy and chemical exergy of the component.

$\dot{\mathrm{Z}}_{K}^{Q}=\sum\left[\dot{Q}_{\mathrm{k}} \frac{T-T o}{T}\right]$, represents thermal exergy flow rate, which gives exergy transfer rate corresponding to the heat transfer rate $\dot{Q}$ when the temperature at the control surface where heat transfer is occurring is $\mathrm{T}$ and the exergy associated with work transfer to and from the control region(KW), if the kth component is condenser then thermal exergy flow rate is zero because the temp difference between the system boundary and the immediate surrounding is zero.

$\mathrm{z}=$ Specific Exergy $(\mathrm{kj} / \mathrm{kg})$

$$
\mathrm{z}=\left(\mathrm{h}-\mathrm{T}_{0} \mathrm{~s}\right)-\left(\mathrm{h}_{0}-\mathrm{T}_{0} \mathrm{~s}_{0}\right)
$$

$\mathrm{h}$ = specific enthalpy $(\mathrm{kj} / \mathrm{kg})$

$\mathrm{s}=$ specific entropy $(\mathrm{kj} / \mathrm{kg})$

$\mathrm{ED}=$ Rate of exergy destruction in the component $(\mathrm{kW}) \dot{\mathrm{W}}$

$=$ Work rate of the system $(\mathrm{kW})$

$r_{\mathrm{r}}=$ mass flow rate of refrigerant $(\mathrm{kg} / \mathrm{s})$

$\mathrm{T}_{\mathrm{r}}=$ Temperature of space to be cooled $(\mathrm{K})$

\subsection{Exergy destruction(ED) of various components}

\subsubsection{Evaporator,}

$$
\begin{aligned}
\mathrm{ED}_{\mathrm{E}}=\dot{\mathrm{Z}}_{6}+\dot{\mathrm{Q}}_{\mathrm{e}}\left(1-\frac{\mathrm{To}}{\mathrm{Tr}}\right)-\dot{\mathrm{Z}}_{1} \\
={ }_{\mathrm{r}}\left[\left(\mathrm{h}_{6}-\mathrm{h}_{1}\right)-\mathrm{T}_{\mathrm{o}}\left(\mathrm{s}_{6}-\mathrm{s}_{1}\right)\right]+\dot{\mathrm{Q}}_{\mathrm{e}}\left(1-\frac{\mathrm{To}}{\mathrm{Tr}}\right)
\end{aligned}
$$

\subsubsection{Compressor,}

$$
\mathrm{ED}_{\text {comp }}=\dot{\mathrm{Z}}_{2}+\dot{\mathrm{W}}_{\text {comp }}-\dot{\mathrm{Z}}_{3}=\dot{\mathrm{m}}_{\mathrm{r}}\left[\mathrm{T}_{\mathrm{o}}\left(\mathrm{s}_{3}-\mathrm{s}_{2}\right)\right]
$$

\subsubsection{Condenser,}

$$
\mathrm{ED}_{\mathrm{c}}=\dot{\mathrm{Z}}_{3}-\dot{\mathrm{Z}}_{4}=\dot{\mathrm{m}}_{\mathrm{r}}\left[\left(\mathrm{h}_{3}-\mathrm{h}_{4}\right)-\mathrm{T}_{\mathrm{o}}\left(\mathrm{s}_{3}-\mathrm{s}_{4}\right)\right]
$$

2.1.4.Liquid vapour heat exchanger (lvhe), $E$. $_{\text {lvhe }}=\left(\dot{Z}_{4}-\right.$ $\left.\dot{\mathbf{Z}}_{5}\right)+\left(\dot{\mathrm{Z}}_{1}-\dot{\mathbf{Z}}_{2}\right)$

$$
=\dot{\mathrm{m}}_{\mathrm{r}}\left[\left(\mathrm{h}_{4}-\mathrm{h}_{5}\right)+\left(\mathrm{h}_{1}-\mathrm{h}_{2}\right)-\mathrm{T}_{\mathrm{o}}\left[\left(\mathrm{s}_{4}-\mathrm{s}_{5}\right)+\left(\mathrm{s}_{1}-\mathrm{s}_{2}\right)\right]\right.
$$

\subsubsection{Throttle Valve,

$$
\mathrm{ED}_{\mathrm{tv}}=\dot{\mathrm{Z}}_{5}-\dot{\mathrm{Z}}_{6}=\dot{\mathrm{m}}_{\mathrm{r}}\left[\mathrm{T}_{\mathrm{o}}\left(\mathrm{s}_{5}-\mathrm{s}_{6}\right)\right]
$$

\subsection{Exergetic Efficiency $\left(\eta_{\mathrm{EE}}\right)$}

Exergetic efficiency is defined as the ratio of minimum exergy required to do a given task to the actual exergy consumed.

$\eta_{\mathrm{EE}}=\frac{\text { minimum exergy required to do a given task }}{\text { actual exergy consumed }}$

Exergetic efficiency is also given by,

$$
\eta_{\mathrm{EE}}=\frac{\dot{\mathrm{Q}}\left(1-\frac{\mathrm{To}}{\mathrm{Tr}}\right)}{\dot{\mathrm{W}} \mathrm{comp}}=\frac{\text { COP vcr }}{\text { COP rev }}
$$

where,

$\mathrm{COP}_{\text {rev }}=$ Coefficient of performance of reversible refrigerator operating between temperature $\mathrm{T}_{\mathrm{o}}$ and $\mathrm{T}_{\mathrm{r}} \mathrm{COP}$ = Coefficient of performance of actual vapour compression cycle.

\subsection{Exergy Destruction Ratio (EDR)}

EDR is defined as the ratio of total exergy destruction in the system to minimum exergy required in doing a given task and is given by,

$$
\begin{aligned}
& \operatorname{EDR}=\frac{\text { ED total }}{\dot{\mathrm{Z}}_{E}^{Q}} \text {, also } \\
& \quad=\frac{\mathrm{COP} \text { rev }}{\mathrm{COP} \mathrm{vcr}}-1=\frac{1}{\eta \text { exergetic }}-1
\end{aligned}
$$

\section{Results and Discussion}

A mathematical computational model is developed for performing exergy analysis of the system using EES software[16]. Following assumptions are assumed during the calculation are:

1) Mass flow rate of refrigerant $\left(\dot{\mathrm{m}}_{\mathrm{r}}\right): 1 \mathrm{~kg} / \mathrm{s}$

2) Steady state components. 3. Effectiveness of liquid vapour heat exchanger $\left(\varepsilon_{\text {lvhe }}\right)=0.74$. Difference between space and evaporator temperature $\left(\mathrm{T}_{\mathrm{r}}-\mathrm{T}_{\mathrm{e}}\right): 16 \mathrm{~K}$

3) Isentropic efficiency of compressor, $\left(\eta_{\text {comp }}\right)=.9$

4) Degree of sub-cooling of liquid refrigerant in lvhe $\left(\Delta \mathrm{T}_{\text {sub }}\right)=5 \mathrm{~K} 7$. Evaporator temperature $\left(\mathrm{T}_{\mathrm{e}}\right): 233 \mathrm{~K}-278 \mathrm{~K}$ 8.Condenser temperature $\left(\mathrm{T}_{\mathrm{c}}\right)$ : $313 \mathrm{~K} 9$. Ambient state temperature $\left(\mathrm{T}_{0}\right)$ : $300 \mathrm{~K} 10$. It is assumed that pressure drop in evaporator, condenser and lvhe is negligible.

Figure 4, depicts clearly the variation of COP with evaporator temperature and following things can be concluded, as we increase the temperature , pressure ratio decreases, which directly reduces the compressor work and finally increases the refrigerating capacity hence leading to a increase in COP of system. It is seen from the calculation that the highest COP is seen in case of R-134a, and closely followed by HFO-1234ze and HFO-1234yf i.e. HFO-1234ze has almost same COP as R-134a. The COP of HFO-134a is $11.81 \%$ is higher then HFO-1234yf respectively, as evaporator temp. increases then COP will have a minimum certain value. Also the COP of HFC-134a is $3.47 \%$ more than HFO-1234ze, which diminishes at higher evaporator temperature. 


\section{International Journal of Science and Research (IJSR) \\ ISSN (Online): 2319-7064}

Index Copernicus Value (2013): 6.14 | Impact Factor (2015): 6.391

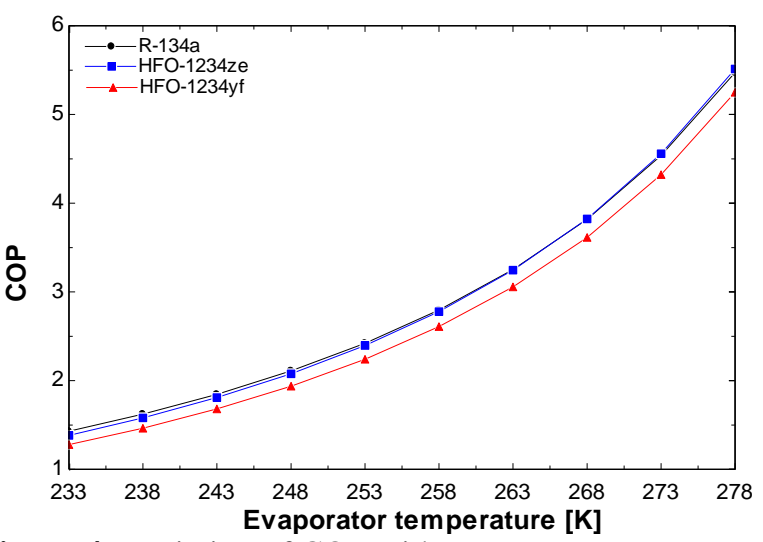

Figure 4: Variation of COP with evaporator temperature

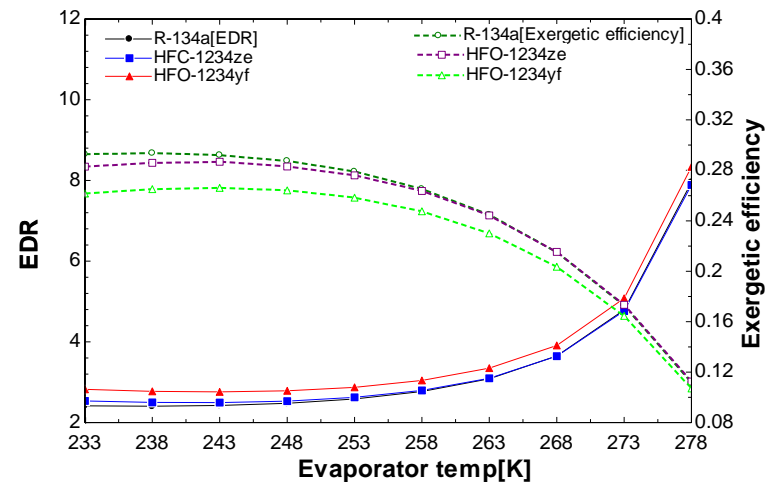

Figure 5: Variation of exergetic efficiency and EDR with evaporator temperature

Fig 5, shows the variation of $\eta_{\text {exergetic }}$ with evaporator temperature. $\eta_{\text {exergetic }}$ first rises and then falls, there are two possible factors for this phenomena to occur. First parameter is thermal exergy flow in the evaporator i.e. $\dot{\mathrm{Q}}_{\mathrm{e}}\left|\left(1-\frac{\mathrm{To}}{\mathrm{Tr}}\right)\right|$, Refrigerating effect increases due to increase in evaporator temperature, but the term $\left|\left(1-\frac{\mathrm{To}}{\mathrm{Tr}}\right)\right|$ decreases since $\mathrm{Tr}$ approaches to To and second factor is compressor work which reduces with the increment in the evaporator temperature i.e. the combined effect of $\dot{\mathrm{Q}}_{\mathrm{e}}$ and $\dot{\mathrm{W}}_{\text {comp }}$ is to increase the $\eta_{\text {exergetic }}$ till it reaches the maximum value and the evaporator temp. at this efficiency is optimum evaporator temperature, beyond which the combined effect is to decrease the $\eta_{\text {exergetic. }} \eta_{\text {exergetic }}$ of $\mathrm{R}-134 \mathrm{a}$ is $11.88-4.29 \%$ higher then HFO-1234yf and also 3.49\% higher then HFO$1234 z e$ at lower end of avaporator temperature and is negligible at higher end of evaporator temperature. Figure 5, also represents the variation of EDR with evaporator temperature and it is opposite to $\eta_{\text {exergetic. Now from the }}$ calculation it can be shown that the EDR of HFO-1234yf is higher then that of HFC-134a and difference decrease in the range 4.76 to $16.81 \%$ respectively as the evaporator temp. increases. For HFO-1234ze the difference is negligible.

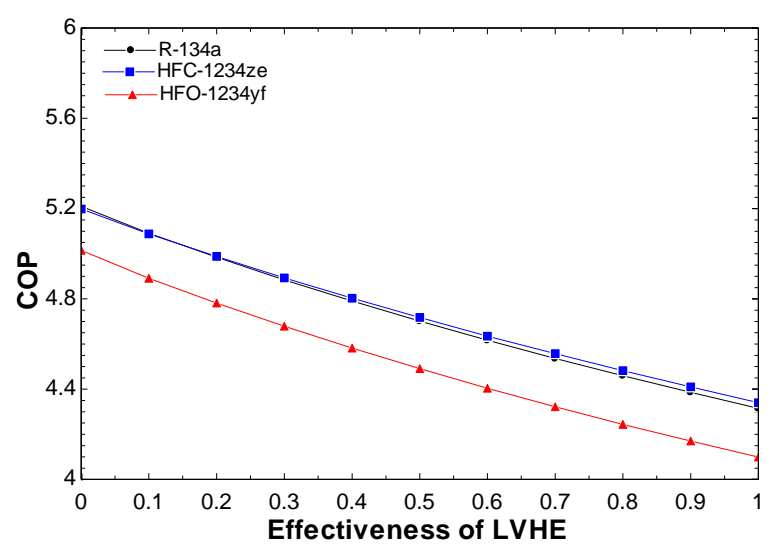

Figure 6: Effectiveness of liquid vapour heat exchanger ( $\varepsilon$, lvhe) vs. COP (Te=273K, Tc=313K).

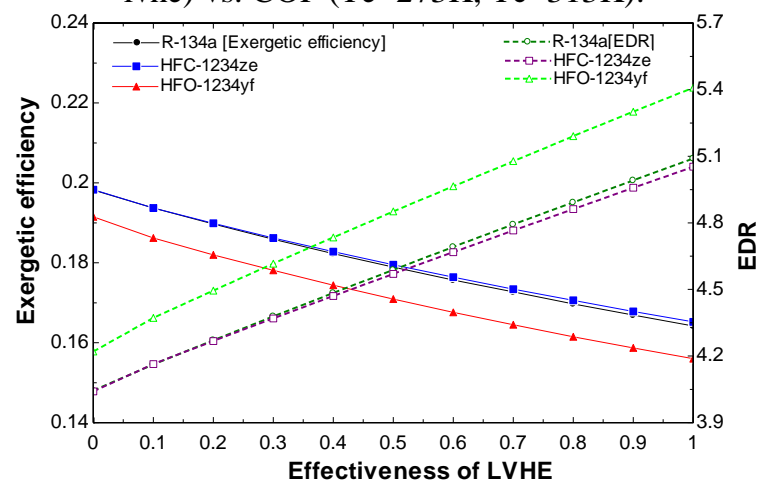

Figure 7: Effectiveness of liquid vapour heat exchanger $(\varepsilon$, lvhe) vs. exergetic efficiency and EDR (Te=273K,

$\mathrm{Tc}=313 \mathrm{~K})$.

Fig. 6-7, shows the effect of effectiveness of lvhe on COP,EDR and $\eta_{\text {exergetic. }}$ With increase in effectiveness of lvhe COP and $\eta_{\text {exergetic }}$ decreases because with increase in effectiveness of lvhe degree of subcooling increases and also superheating of suction vapour takes place i.e. increase in compressor work whereas EDR increases for all the refrigerants taken for the consideration. The effect of increase in refrigerating effect is counteract by increase in compressor work hence COP of system decreases. COP of the system decreases by $20.74 \%$ for HFC-134a, 19.76 for HFO-1234ze, 22.34\% for HFO-1234yf. It is clearly shown that COP decrease highest in case of HFO-1234yf. Similar trends have been shown by $\eta_{\text {exergetic }}$ curves.

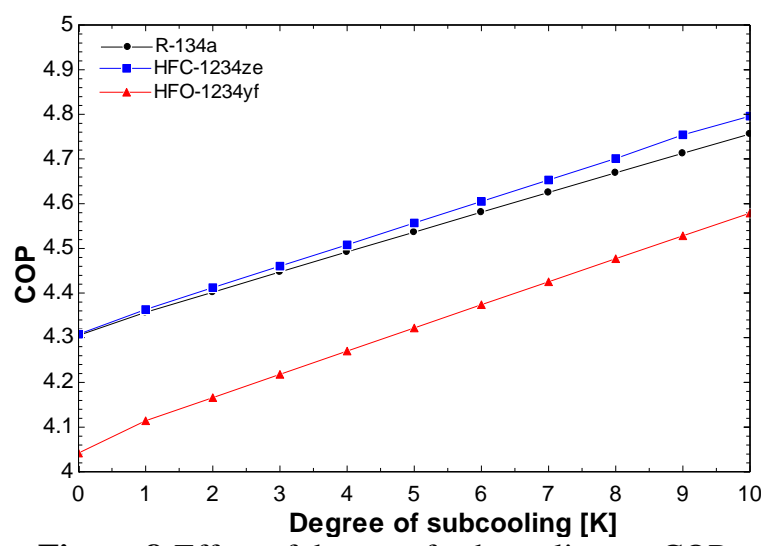

Figure 8:Effect of degree of sub-cooling on COP $(\mathrm{Te}=273 \mathrm{~K}, \mathrm{Tc}=313 \mathrm{~K})$. 


\section{International Journal of Science and Research (IJSR) \\ ISSN (Online): 2319-7064}

Index Copernicus Value (2013): 6.14 | Impact Factor (2015): 6.391

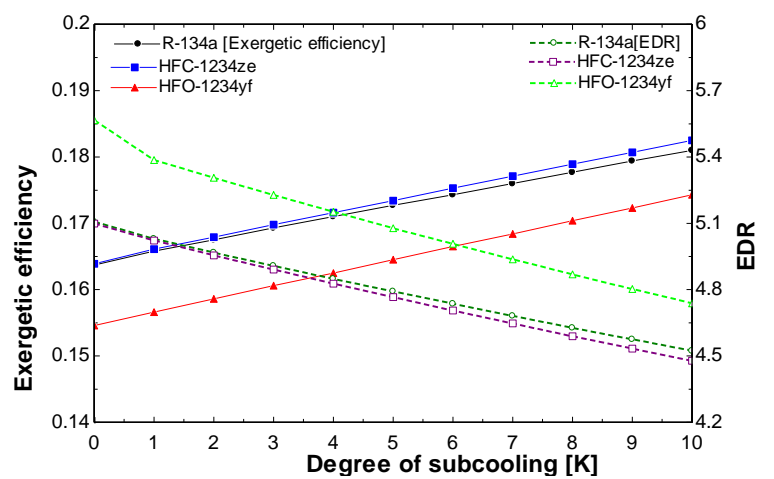

Figure 9: Effect of degree of sub-cooling $(\Delta \mathrm{Tsub})$ on exergetic efficiency and EDR $(\mathrm{Te}=273 \mathrm{~K}, \mathrm{Tc}=313 \mathrm{~K})$.

Fig.8-9,shows the effect of degree of subcooling temperature on COP, EDR and $\eta_{\text {exergetic. With increase in degree of }}$ subcooling temperature, $\eta_{\text {exergetic }}$ increases, EDR decrease. Increase in subcooling increases the refrigerating effect which increases COP. For HFO-1234yf shows least $\eta_{\text {exergetic }}$ and COP, closely followed by HFO-1234ze and HFC-134a. The total increase in COP for $10 \mathrm{~K}$ degree of subcooling is $10.47 \%$ for HFC-134a, $11.32 \%$ for HFO-1234ze, and the maximum increase has seen for HFO-1234yf i.e. 13.28\%. Similar trends have been shown by exergetic efficiency curves.

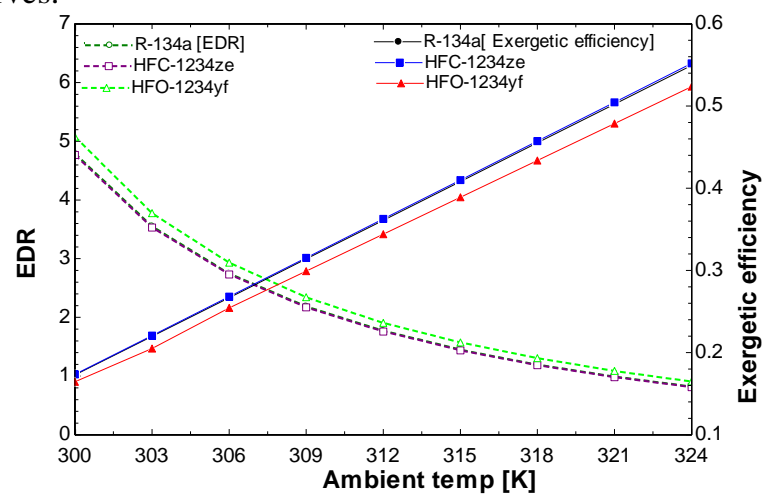

Figure 10: Variation of exergetic efficiency and EDR with ambient state temperature $(\mathrm{Te}=273 \mathrm{~K}, \mathrm{Tc}=313 \mathrm{~K})$.

Figure 10, shows the variation of ambient state temperature for $\eta_{\text {exergetic }}$ and EDR. With increase in ambient temperature, $\eta_{\text {exergetic }}$ increases and EDR reduces, because of the increment in the term $|(1-\mathrm{To} / \mathrm{Tr})|$, while the term $\dot{\mathrm{Q}}_{\mathrm{e}}$ and $\dot{\mathrm{W}}_{\text {comp }}$ remains constant. HFO-1234ze and HFC-134a shows the similar trends and their curves for $\eta_{\text {exergetic }}$ and EDR are almost overlapping. HFO-1234yf shows least values for $\eta_{\text {exergetic }}$ and higher values for EDR then other refrigerants.

\section{Conclusions}

In the energy and exergy analysis of HFO-1234ze, HFO1234yf and HFC-134a in a actual vapour compression cycle incorporated with a liquid vapour heat exchanger, following conclusion can be made which are summarized below.

1) $\mathrm{COP}$ and $\eta_{\text {exergetic }}$ of:

a) HFO-1234ze and HFC-134a is almost same having a difference of $3.47 \%$ which decreases with increase in evaporator temperature. Hence HFO-1234ze can be good replacement of HFC-134a with certain modification.
b)HFC-134a is $11.81-4.24 \%$ more than HFO-1234yf. Hence HFO-1234yf can be a good drop in replacement of HFC-134a at higher values of evaporator temperature.

2) From the exergy destruction viewpoint or irreversibility, the worst component is condenser, throttle valve, compressor, evaporator and lvhe is the most efficient one

3) With increase in ambient temperature $\eta_{\text {exergetic }}$ increases on the contrary EDR decreases. HFO-1234yf shows least values for $\eta_{\text {exergetic }}$ and higher values for EDR, closely followed by HFO-1234ze and HFC-134a.

4) HFC-134a gives higher COP and $\eta_{\text {exergetic }}$ than HFO$1234 y f$ but less value then HFO-1234ze. However reverse is true when effectiveness of lvhe is increased from 0 to 1.

5) And hence hydrofluoroolefins are best alternative replacement of HFC-134a in refrigeration application.

\section{References}

[1] B. Minor and M. Spatz, "HFO-1234yf low GWP refrigerant update," In: International Refrigeration and Air Conditioning Conference at Purdue, West Lafayette, IN, USA, Paper No. 2349, 2008.

[2] C. Zilio, S.S. Brown and A. Cavallini, "Simulation of R-1234yf performance in a typical automotive system.," Proceedings of the 3rd Conference on Thermophysical Properties and Transfer Processes of Refrigeration, Boulder, CO, USA, Paper No. 128, 2009.

[3] O.J. Nielsen, M.S. Javadi, A. Sulbak, M.D. Hurley, T.J. Wallington and R. Singh, "Atmospheric chemistry of $\mathrm{CF} 3 \mathrm{CF}=\mathrm{CH} 2$ : kinetics and mechanisms of gas-phase reactions with $\mathrm{Cl}$ atoms, $\mathrm{OH}$ radicals, and $\mathrm{O} 3$," Chem. Phys. Lett., 439, 18-22, 2007.

[4] J.S. Brown, "HFOs - New, Low Global Warming Potential Refrigerants," ASHRAE Journal, 22-29, 2009.

[5] M. Mohanraj, S. Jayaraj and C. Muraleedharan, "Environment friendly alternatives to halogenated refrigerants - a review," Int. J. Greenhouse Gas Control, 3, 108-119, 2009.

[6] United Nations Environmental Programme, "Montreal Protocol on Substances that Deplete the Ozone Layer, Final act," New York, United Nations, 1987.

[7] Global Environmental Change Report, "A Brief Analysis of the Kyoto Protocol, IX," P.24, 1997.

[8] "Official Journal of the European Union," Directive 2006/40/EC of the European Parliament and of the Council, 14.6.2006.

[9] E.W. Lemmon, M. L. Huber and M. O. McLinden, "NIST Standard Reference Database23:Reference FluidThermodynamic and Transport Properties,' REFPROP, Version 9.0. National Institute of Standards and Technology, Standard Reference Data Program. Gaithersburg, 2010.

[10]T.J. Leck, "New High Performance, LOW GWP Refrigerants for Sationary AC and Refrigeration," 13th International Refrigeration and Air Conditioning Conference at Purdue, West Lafayette,2160,1-8,2010.

[11] S.F. Yana Motta, E.D. Vera Becerra and M.W. Spatz, "Analysis of LGWP Alternatives for Small Refrigeration (Plugin) Applications," 13th International Refrigeration and Air Conditioning Conference at Purdue, West Lafayette, 2499, 1-7, 2010. 
[12] D. Jung, Y. Lee and D. Kang, "Performance of virtually non-flammable azeotropic HFO1234yf/HFC134a mixture for HFC134a applications," International Journal of Refrigeration 36,1203-1207,2013.

[13]D. Leighton, Y. Hwang and R. Radermacher, "Modeling of Household Refrigerator Performance with LGARs," ASHRAE Winter Conference, Chicago,2012.

[14]O. Abdelaziz, K.M. Karber and E.A. Vineyard, "Experimental Performance of R-1234yf and R-1234ze as Drop-in Replacements for R-134a in Domestic Refrigerators," 14th International Refrigeration and Air Conditioning Conference at Purdue, West Lafayette, 2241, 1-10, 2012.

[15]P. K. Nag, Engineering Thermodynamics, Available energy, Availability and Irreversibility, Tata McGraw Hill Education private limited, 209-240,2011.

[16]S.A. Klein and F. Alvarado, Engineering Equation Solver, F Chart software, Middleton, WI, Version9.224,2012.

[17] E. Navarro, I.O.M. Galvan, J.G. Macia, Comparative experimental study of an open piston compressor working with R-1234yf, R-134a and R-290, Int. J. Refrig. 36 (2013) 768e775.

[18]Zhaogang Qi Experimental study on evaporator performance in mobile air conditioning system using HFO-1234yf as working fluid.

[19] C.P.Arora hand book.

[20]C.C. Wang, An overview for the heat transfer performance of R-1234yf, Renew.Sustain. Energy Rev.19(2013)444e453.

[21] Sad Jarall Study of refrigeration system with HFO$1234 y f$ as a working fluid

\section{Author Profile}

Shobhit Mishra is currently pursuing masters degree program in Thermal engineering in Department of Mechanical Engineering, Jamia Millia Islamia, Delhi ( India),

M. Emran Khan Professor Mechanical Engineering Department, Jamia Millia Islamia, Delhi, (India) 